\title{
Students Perceptions and Feedback on Ragging in a South Indian Medical College
}

\begin{abstract}
Samson S R Nallapu ${ }^{1}$
Abstract

Introduction: Ragging is associated with physical, behavioural, emotional and social problems among victims. Some reasons given by students for ragging are: being ragged by their seniors; sense of superiority; a form of introduction.

Methodology: Emerging themes and insights from in-depth interviews and group discussions with senior students helped in preparing a Likert type questionnaire on certain important aspects of ragging and the precautions being taken by the management. This was administered to 240 medical students from the 5th and 7th semesters (batches of 2008 \& 2009) of the NRI Medical College at Chinakakani in Guntur District of Andhra Pradesh. Group discussions also were conducted with students to identify issues on ragging.
\end{abstract}

Results \& Discussion: Forty-five percent of the students felt that some amount of ragging does occur. Almost all (99\%) felt that ragging is necessary to build a relationship between seniors and juniors. Eighty-seven percent of seniors expected the juniors to address them as "Sir" or "Madam". Discussions revealed that economic background was not an indicator for those indulging in ragging. Many felt that some interaction is needed between new students and seniors, but that any form of interaction may be misconstrued as ragging.

Conclusion: Students have to be made aware of the ills of ragging and its consequences. The management also has the responsibility to create safe avenues for healthy interaction of new students with seniors. Some methods include organizing activities under supervision of teachers, individual counselling of students, seminars and workshops on self- esteem.

Key words: medical students, juniors, seniors, issues, feed back

\section{Introduction}

The issue of ragging in professional colleges has always been a much discussed topic. The recent spate of student deaths in India, allegedly due to ragging by senior students, has taken the country by storm. Families and political groups are urging the government to clamp down heavily on ragging in any form. The government has given all college managements strict guidelines and warnings regarding ragging on and off campus.

\footnotetext{
${ }^{1}$ Associate Professor,

Department of Community Medicine, NRI Medical College, Chinakakani, Guntur District, Andhra Pradesh, India.

Corresponding author:

Dr. Samson S R Nallapu

Department of Community Medicine, NRI Medical College,

Chinakakani, Guntur District, Andhra Pradesh, India.

E mail: samson.nallapu@yahoo.com
}

The term "ragging" can be applied to any unruly behaviour that involves mocking or treating any student offensively so as to cause nuisance, frustration or feelings of fear so as to adversely affect his or her state of mind. Ragging is practiced all over the world, with different nomenclature such as hazing, fagging etc. Ragging has been frequently associated with a broad spectrum of physical, behavioural, emotional and social problems among the victims. It independently increases suicide risks. Some reasons given by students for ragging (Garg, 2009) are; being ragged by seniors; sense of superiority; and a means of introduction.

Ragging is an age old practice in most professional institutions, where in-coming junior students are subjected to a certain amount of "good natured" teasing by seniors. This is intended to break the ice and also 
allows juniors to get to know seniors. However, there is always a possibility of conflict arising from the inherent diversity of individual students' nature both amongst seniors and juniors. This deviation leads to unexpected and disastrous outcomes. This practice has come under strict public scrutiny and strong pleas have been made to do away with ragging.

The Medical Council of India (MCl, 2009) has identified as an objective the elimination of ragging in all forms from medical colleges/ institutions in the country by prohibiting it by law, preventing its occurrence by following certain regulations and punishing those who indulge in ragging.

According to the observations by the $\mathrm{Dr}$. Raghavan Committee, which has been constructed by the Union Human Resource Development Ministry on the orders of the Honourable Supreme Court of India, medical colleges are the most affected in India. Ragging should not be "an annual tradition". A loss of self-control in search of fun is the initiator of ragging. It continues on for about a month or so, then things are back to normal. According to reports the victims are solely the freshmen. Rao (2010) comments that in foreign countries, ragging of the sort found in India was unheard of. Ragging is a serious violation of human rights.

Ragging not only is a socio-legal problem but also has a certain psychological basis. Possible reasons that initiate ragging include giving a sense of authority to seniors, being a means of retaliation (previous history of being ragged and a way of getting back by venting his frustrations on the freshmen), satisfaction of sadistic pleasures, peer pressure and that ragging makes a "fashion statement". Many senior students live under the misconception that ragging makes a style statement and will put them in the 'influential crowd' of their college (Chopra, 2009). Agarwal (2005) notes that in India, a myth that ragging makes students bold has always existed. This has given a passive social acceptance to this practice. As long as this exists ragging will never see its demise.

Agarwal et al. (2007) comment on the Raghavan committee recommendation that ragging should be considered an important factor in accrediting educational institutions by central regulatory bodies, such as the $\mathrm{MCl}$. This would not only make educational institutions take serious steps against ragging but would also make these central regulatory bodies accountable. The committee made an observation that ragging indeed affects the quality of education.

Ragging is the biggest fear of any student entering college, especially those moving away from home to live in hostels. Agarwal et al. (2007) suggest that ragging is a criminal problem which has psychological roots and is a social ignorance. It is somewhat like giving a dowry. The magnitude of the problem is so enormous that a top-down law enforcement approach may not be adequate to solve it.

"...What was intended to be in good faith and provide untainted fun is now characterized as physical torture with a sadistic tendency and sexual perversions. There are few reported cases of loss of life. One thing is clear that ragging, which was originally thought of to be a mere joke, has crossed bounds of decency and had entered the arena of physical and mental torture. It needs to be dealt with iron hands..." (Raghavan et al., 2006).

The NRI Medical College has a reputation for excellent training in medical and allied health sciences in this part of the country. While ragging is almost non-existent in the institution, the management has decided to further strengthen the anti-ragging measures. Actions taken by the management include formation of an anti-ragging committee, guest lectures by senior legal and police personnel, changing of class timings for freshmen, faculty members accompanying students' buses for the first couple of months, etc. In this regard, the present study was conducted to look into the awareness of the students and attempt to understand their perceptions and reactions.

\section{Methods}

This study was conducted for 5 months from July to November 2011 involving 240 senior medical students from the 5th and 7th semesters (batches of 2008 \& 2009) of the NRI Medical College situated at Chinakakani in Guntur District of Andhra Pradesh, India. Emerging themes and insights from in-depth interviews and focus group discussions with the students helped in preparing a Likert type questionnaire on ragging in professional colleges. The questionnaire with twenty key questions on various aspects of ragging was pretested on some students and suitable modifications were made. Some of the questions included whether ragging was prevalent in the institution, what exactly 
constitutes ragging in the students' opinion, socioeconomic factors regarding ragging, the need for ragging as a practice, and if it can happen in a controlled environment under faculty supervision, etc. This questionnaire was administered to the medical students after consent was given. Students were able to write down any remarks they wished to make on ragging and the management of anti ragging measures. Students were assured anonymity to encourage honest answers.

The information obtained was entered in MS Excel, analysed and presented as percentages. Though an attempt was made to look at individual scores, there was no significant variation in the responses of the students either between girls and boys or between batches. The qualitative data was transcribed and categorized for emerging issues and themes.

\section{Results}

Ninety-nine percent of students in this study (Table 1) felt that a little bit of ragging is necessary to build a relationship between seniors and juniors. As one student stated,

"Ragging should be an interaction. The awareness created by the college authorities now is creating a Monster like image of seniors".

Another student said,

"An introduction/interaction is a must with seniors. It helps juniors to develop personally / educationally. At the same time the interaction /ragging shouldn't cross the limits of humanity."

Table 1: Student perceptions on need for ragging $(n=240)$

\begin{tabular}{|c|c|c|c|}
\hline S.No & Question & $\%$ Agree & \% Disagree \\
\hline 1 & $\begin{array}{l}\text { If juniors do not go through the process of ragging, they cannot be } \\
\text { put in place }\end{array}$ & 88 (SA 52\%) & $12(\mathrm{SD} 5 \%)$ \\
\hline 2 & $\begin{array}{l}\text { Juniors can show respect for seniors by addressing them as Sir or } \\
\text { Madam }\end{array}$ & 85 (SA 64\%) & $15(\mathrm{SD} 4 \%)$ \\
\hline 3 & $\begin{array}{l}\text { A little bit of ragging is necessary to build a relationship between the } \\
\text { seniors and juniors }\end{array}$ & 99 (SA 81\%) & $1(\mathrm{SD} 0 \%)$ \\
\hline 4 & $\begin{array}{l}\text { Ragging, if done properly, is enjoyable to both new and old } \\
\text { students. }\end{array}$ & 95 (SA 65\%) & $5(\mathrm{SD} 1 \%)$ \\
\hline 5 & Being ragged as a junior improves abilities of interaction. & 68 (SA 21\%) & $32(\mathrm{SD} 8 \%)$ \\
\hline 6 & $\begin{array}{l}\text { Concern about the lack of a minimum amount of interaction with the } \\
\text { juniors. }\end{array}$ & $94(\mathrm{SA} 87 \%)$ & $6(\mathrm{SD} 2 \%)$ \\
\hline
\end{tabular}

*SA: Strongly agree, SD: Strongly Disagree

One issue noted was that $85 \%$ seniors expected juniors to address them as "Sir" or "Madam". In fact, $64 \%$ of the students strongly agreed to this. According to another student,

"Mild form of ragging is essential for juniors for interaction, so that the seniors might be helpful in clinicals for juniors. MBBS is a course where we can learn a lot from seniors".

Eighty eight percent believed that if juniors did not go through the ragging process they cannot be put in place. Ninety-five percent (228) felt that ragging if done in a proper way is enjoyable to both seniors and juniors.

Though ragging is prohibited in the institution, about $45 \%$ (108) of the students felt that some amount of "ragging" does occur (Table 2). The definition of ragging by the authorities came under a lot of criticism. Eighty-five percent of the students did not accept that just asking a junior his or her name or any other detail, should be considered ragging.

"Mild interaction is needed; otherwise, juniors would not give minimum respect to seniors" said one student. "Ragging is a form of interaction. Don't try to totally prevent it. In such case there will be no respect for the seniors. Please don't spoil it."

Seventy four percent (178) of students strongly disagreed to the abolishment of ragging. As one student stated,

"Ragging, like any other issue is a two edged sword. If perceived in a positive sense it is really useful for the further years in the medical college." 
One student exclaimed, "I was a junior once. It didn't harm me. Further it improved my abilities of interaction."

A good number of the students (83\%) felt that juniors may take advantage of the anti-ragging laws and use them to falsely implicate the seniors by making complaints. Fifty-one percent felt that the authorities could arrange avenues for interaction between seniors and juniors under faculty supervision.

Fifty-eight percent of the students (Table 3 ) felt that there were some students who took ragging beyond proper limits.
"Take severe action on some seniors who indulge in severe ragging; by keen identification", suggested one student.

"Ragging should be within limits. It should not include humiliation or discrimination."

When asked if stories on ragging were enjoyable to listen to, $59 \%$ disagreed. One student said,

"By virtue of personal experience, everyone enjoys sharing such experiences".

Table 2: Views on ragging and opinion about the authorities' action (n=240)

\begin{tabular}{|c|c|c|c|}
\hline S.No & Question & $\%$ Agree & \% Disagree \\
\hline 1 & Ragging (mild, moderate or severe) does not occur in this college. & 45 (SA 14\%) & $55(S D 11 \%)$ \\
\hline 2 & Definition of ragging by the authorities is not acceptable. & $73(\mathrm{SA} 35 \%)$ & $27(\mathrm{SD} 5 \%)$ \\
\hline 3 & $\begin{array}{l}\text { Calling a junior and asking his / her name and other details is also } \\
\text { considered ragging. }\end{array}$ & $15(\mathrm{SA} 2 \%)$ & $85(\mathrm{SD} 77 \%)$ \\
\hline 4 & $\begin{array}{l}\text { Juniors may misuse the anti ragging measures by giving wrongful } \\
\text { complaints about their seniors. }\end{array}$ & $83($ SA 62\%) & $18(S D 13 \%)$ \\
\hline 5 & Abolishing ragging is necessary for a healthy student community. & 26 (SA 5\%) & $74(S D 64 \%)$ \\
\hline 6 & $\begin{array}{l}\text { Organising activities which allow the interaction of students under } \\
\text { supervision of the teachers }\end{array}$ & $87($ SA $51 \%)$ & $13(\mathrm{SD} 5 \%)$ \\
\hline
\end{tabular}

*SA: Strongly agree, SD: Strongly Disagree

Table 3 Ragging and its limitations according to students ( $n=240)$

\begin{tabular}{|c|c|c|c|}
\hline S.No & Question & $\%$ Agree & \% Disagree \\
\hline 1 & $\begin{array}{l}\text { Ragging should be within limits. It should not include humiliation or } \\
\text { discrimination. }\end{array}$ & $98(\mathrm{SA} 83 \%)$ & $3(\mathrm{SD} 0 \%)$ \\
\hline 2 & Some students do take ragging beyond proper limits. & $58(\mathrm{SA} 28 \%)$ & $42(\operatorname{SD} 5 \%)$ \\
\hline 3 & $\begin{array}{l}\text { Hearing stories on how other students (in or outside the college) } \\
\text { were ragged is enjoyable. }\end{array}$ & $41(\mathrm{SA} 7 \%)$ & $59($ SD 35\%) \\
\hline 4 & $\begin{array}{l}\text { Senior students who were ragged as students usually rag their } \\
\text { junior students }\end{array}$ & $54(\mathrm{SA} 34 \%)$ & $46($ SD $20 \%)$ \\
\hline 5 & $\begin{array}{l}\text { Junior students from poor socio economic background may take } \\
\text { even mild ragging demeaningly.in a bad way }\end{array}$ & $33(\mathrm{SA} 14 \%)$ & 67 SD 19\%) \\
\hline 6 & $\begin{array}{l}\text { Usually students from either the richest or poorest background } \\
\text { indulge in ragging }\end{array}$ & $5(\mathrm{SA} 2 \%)$ & $95(\mathrm{SD} 82 \%)$ \\
\hline 7 & Some of us will indulge in ragging of a severe nature. & 77 (SA 32\%) & $23($ SD $10 \%)$ \\
\hline 8 & $\begin{array}{l}\text { Severe action should be taken on seniors who indulge in serious } \\
\text { ragging }\end{array}$ & 91 (SA 57\%) & 9 (SD 0\%) \\
\hline
\end{tabular}

*SA: Strongly agree, SD: Strongly Disagree 
Fifty-four percent agreed that those who were ragged would most probably want to rag their juniors in turn. Concerning socioeconomic status of the new students and their sensitivity to ragging, $67 \%$ felt that it made no difference. Most disagreed that it was the poorest or richest seniors who indulged in ragging.

"Economic background is not an indicator for those indulging in ragging (aggressive personalities). Similarly sensitive students (juniors) will take ragging seriously. This again is regardless of economic background".

Finally, $91 \%$ of the students agreed that strict action should be taken against those who indulged in serious forms of ragging.

\section{Discussion}

Ragging is a problem of the students and by the students, so the solution lies with the students. Even today, after the extreme aftermath of ragging, many students support harmless or healthy ragging; for some it is painful torture but others consider it a personality development exercise (Parvathi, 2010). The above findings make it obvious that senior students are strongly concerned about the lack of a minimum amount of interaction with juniors. Attempts by the management to keep them apart are viewed with apprehension. Many felt that it is a threat to the very fabric of student life. In spite of the best efforts of the management to remove all forms of ragging from the campus, it is seen here that students still find some way to interact with the new comers.

Chopra (2009) suggests that there are forms of ragging that range from bad to worse. Agarwal (2005) classifies them as Dress Code Ragging, Formal Introduction, Verbal Torture, Sexual Abuse, Playing the Fool, Hostel Ragging, and Drug Abuse. Again the issue arises whether the authorities can ignore even the simple forms of ragging.

This study also shows that most students do not seem to understand the psycho-social aspect of ragging. They also do not see that some sensitive students may be affected severely by even the mildest form of ragging or it's far reaching consequences.

Many senior students are under the impression that ragging is a tradition that is enjoyed by all, including the new comers. They do agree that it should not cross certain limits. However each student has a different threshold or capacity to take any form of intimidation or ridicule by a peer or a senior. To some, even a minor remark may start a process of discouragement and despair leading to extreme results, especially when students entering professional colleges are removed from their homes and put in a new and challenging atmosphere. In a large group of students, there is no way to identify the personalities of each new student and assess the amount of ragging he or she can handle. The senior students are definitely in no position to make such an evaluation. It is apparent in this study that when ragging takes place, it does so uniformly for all the new students and keeps increasing in severity depending on the personalities and aggressive natures of the seniors conducting the ragging. Words, such as "limited" ragging, "simple" ragging or "healthy" ragging should not exist. Therefore, it is imperative that all forms of ragging has to be removed completely from educational institutions.

Seniors work laboriously to be identified and respected by their juniors. Seniors are firm in their belief that ragging is one way to ensure the respect of their juniors. Seniors are afraid that if juniors do not go through the ragging process, they would not know their place. It is noted that senior students expect to be called "Sir" or "Madam" by their juniors. Most of the students felt that a little bit of ragging was necessary to build a relationship between the seniors and juniors.

Some of the students' comments were:

"The management is doing a lot of over action regarding ragging."

"The hostel is like a jail."

"There is no friendly environment in the Medical College."

All junior students have been given a toll free number to inform the police if he/she was being intimidated by a senior. A fear that has cropped up is that the new comers may misuse the anti ragging measures.

"Healthy ragging is required to build a good relation. Juniors shouldn't rag us with the toll free number."

"There is a chance juniors may wrongfully complaints about their seniors, even without any severe ragging." 
It is seen in this study that there are some students who will indulge in severe ragging. The students agree that such people need to be identified and monitored. However, they want the management to keenly observe and identify the perpetrators. Looking into the characteristics of those who practice severe forms of ragging, students agree that it is not the very rich or poor students who engage in ragging.

\section{Conclusion}

\section{A senior student's comment:}

"Don't try to avoid interaction. But try to remove fear from them."

The Supreme Court of India has pronounced that educational institutions should obtain an undertaking from each candidate at the time of admission that he / she is aware of the system of ragging punishment from senior students. If he / she is involved in any ragging he/she is aware of the scale of punishments which including criminal action, cancellation of admission, expulsion from the hostel, withdrawal of scholarship and rigorous imprisonment up to three years, etc.

Unfortunately, ragging does not have a quickfix solution. Passing a law or even implementing it will not solve the problem. We must understand that unless society condemns it, ragging cannot be eliminated (Garg, 2009). Many parents and the public do not take ragging seriously and have not advised their wards on how to cope with ragging.

The Andhra Pradesh State in its Prohibition of Ragging Order recommends that students who are involved in ragging, have it noted on their marks cards and other academic certificates, embossed in bold letters and which cannot be obliterated that they had indulged in ragging and had conducted themselves in a manner unbecoming of a student (Raghavan, 2006).

While abolishment of decadent practices such as ragging from professional colleges is a necessity, the managements also have the responsibility to create safe avenues for healthy interaction of new coming students with seniors. The very nature of a professional course calls for an extended period of study to gain knowledge through all possible avenues. One of the important opportunity to gain knowledge and change attitudes and behaviours is through interaction with other students, especially seniors.

One approach is organising activities which allow the interaction of students (seniors and juniors) under the supervision of faculty members. Individual counselling, additional discourses, seminars and workshops on self esteem, leadership, motivation etc are other methods.

A sharp look out for students who are prone to anti-social activities and regular monitoring and counselling of such identified individuals is necessary. A sense of pride and achievement may be ushered into the institution so that a student (junior or senior) can confidently say that "Ours Is a Ragging Free Campus!" Finally, it is seen that in sensitive topics such as ragging soft data collected through qualitative methods yields useful information.

\section{Acknowledgements}

The author wishes to acknowledge the contributions all students who participated in the study. The author is also grateful to the management of the NRI Medical College for giving necessary consent to conduct the study and also their sincere efforts to curb the menace of ragging.

\section{References}

Agarwal, H., Aggarwal, V. \& Garg, M. (CURE Report (July 2007). Raghavan Committee Report - A brief analysis. Coalition to Uproot Ragging from Education (CURE) CURE REPORT CR2007/07-16 Issue Date: July 16, 2007 - www.noragging.com.

Agarwal, H., Aggarwal, V., Garg, M., Asthana, A., Swamy, V., Ram, R. \& Sharma, DR. CURE Report (May 2007) Ragging in India. A Summary Report on Incidents, Social Perceptions and Psychological Perspectives .CURE REPORT: CR2007_05-16. May 16, 2007.

Agarwal, H (2005) Ragging: History and Evolution CURE REPORT CR2005/07-27 Issue Date: July 28, 2005 available from: http://noragging.com/ index.php/Research/Reports/Ragging-Historyand-Evolution.html.

Andhra Pradesh Prohibition of Ragging in all educational institutions Rules 2002 (G.O Ms .No.67, Higher Education (EC) 31st August ,2002) Available from: http://ebookbrowse.com /ap-prohibition-of-ragging-in-all-educationalinstitutions-rules-2002-pdf-d385002144. 
Chopra, M. (2009) Ragging In Educational Institutes: A Human Rights Perspective. - Guru Gobind Singh Indraprastha University, Delhi. Available from: http://www.legalserviceindia. com /articles/ragging.htm.

Garg, R. (2009) Ragging: A public health problem in India, Indian Journal of Medical Science, 63, pp.263-271.

Medical Council of India (Prevention and Prohibition of Ragging in Medical Colleges/Institutions) Regulations, 2009. Medical Council of India Notification, New Delhi, 3rd August, 2009 No. MCl- 34(1)/2009-Med./25453, http://www. mciindia.org /RulesandRegulations/ Prevention ofRaggingRegulation2009.aspx
Parvathi, S. (2010) Menace of ragging in educational institutions - A critical study, The National University of Advanced Legal Studies (NUALS) Available from: http://www.answering law.com/php/displayContent.php?linkld=1072.

Raghavan, R.K., Dhande, S.G., Agarwal, A.K., Prasad, R., Krishnamurthy, C., Sathikh, S. \& Kumar, S., (2006) The Menace of Ragging In educational Institutions and measures to curb it: Report of the Committee constituted by the Hon'ble Supreme Court of India In SLP No. 24295 of 2006. Available from: http://www.ugc.ac.in/ragging.pdf .

Rao, Y.S. (2010) Ragging, Available from: http://www.airwebworld.com/articles/index.php? article $=1401$ 